\title{
Morphological Transformation and Phosphatidylserine Exposure in Erythrocytes Treated with Ribavirin
}

\author{
Masato Homma, ${ }^{*}, a, b$ Hiroyuki Hosono, ${ }^{a}$ Yuichi Hasegawa, ${ }^{c}$ and Yukinao KohdA ${ }^{a, b}$ \\ ${ }^{a}$ Department of Pharmacy, Tsukuba University Hospital; 2-1-1 Amakubo, Tsukuba, Ibaraki 305-8576, Japan: \\ ${ }^{b}$ Department of Pharmaceutical Sciences, University of Tsukuba; and ${ }^{c}$ Department of Hematology, Graduate School of \\ Comprehensive Human Sciences, University of Tsukuba; 1-1-1 Ten-nodai, Tsukuba, Ibaraki 305-8575, Japan. \\ Received June 8, 2009; accepted July 25, 2009; published online August 24, 2009
}

\begin{abstract}
The effects of intracellular ribavirin on morphology and redistribution of phosphatidylserine (PS) in human erythrocytes were examined. Erythrocytes were incubated with $1 \mathrm{~mm}$ ribavirin in the presence/absence of dipyridamole, an inhibitor of es-type nucleoside transporter. Intracellular ribavirin was accumulated in erythrocytes with the concentration of $1361 \mu \mathrm{M}$, which corresponds to the blood level in patients receiving ribavirin. Dipyridamole reduced ribavirin accumulation by $40.7 \%(807 \mu \mathrm{M})$ via inhibiting es-type nucleoside transporter on erythrocytes. Morphological transformation into echinocytic form was observed in $\mathbf{8 6 . 4 \%}$ of the erythrocytes treated with ribavirin. Dipyridamole pre-treatment decreased the morphological change to $20.0 \%$. Ribavirin increased the PS-exposing cells compared with control (2.15\% vs. $0.87 \%)$. PS-exposing cells were also decreased by inhibiting ribavirin accumulation with dipyridamole $(0.62 \%)$. The results suggest that intracellular ribavirin induces morphological change and PS exposure in erythrocytes and accelerates erythrophagocytosis in the reticuloendothelial system.
\end{abstract}

Key words ribavirin; erythrocyte; phosphatidylserine exposure; morphological transformation

Ribavirin (1- $\beta$-D-ribofuranosyl-1 $H$-1,2,4-triazole-3-carboxamide), a synthetic guanosine analogue, is phosphorylated intracellularly to exert antiviral activities against DNA and RNA viruses. ${ }^{1,2}$ Combination therapy with interferon (IFN) for hepatitis $\mathrm{C}$ virus (HCV) infection revealed that higher rate of sustained virus response was achieved by adjuvant effects of ribavirin. ${ }^{3-5)}$ One of the major side effects of ribavirin is a reversible hemolytic anemia, which sometimes necessitates cessation of ribavirin co-administration. ${ }^{6-8)}$ Ribavirin-induced hemolytic anemia is likely due to excessive accumulation of phosphorylated ribavirin in erythrocytes. ${ }^{9-12)}$ Once incorporated into erythrocytes via es-type nucleoside transporter, ${ }^{13)}$ ribavirin is subjected to intracellular phosphorylation and converted to its phosphorylated metabolites. ${ }^{14)}$ Therefore the concentration of erythrocyte ribavirin including phosphorylated metabolites is 160 -fold higher than that in plasma. ${ }^{9,10)}$

Recent studies have revealed that erythrocyte ribavirin induced intracellular ATP deficiency, leading to downregulation of the hexose monophosphate shunt resulting in accelerated oxidative damage on erythrocyte cell membrane. ${ }^{15)}$ Significant alterations including band 3 aggregation were also found; these are known associated with erythrophagocytosis in reticuloendothelial system (RES). ${ }^{15)}$ Intracellular ATP deficiency may cause ATP-dependent morphological transformation $^{16)}$ and enzyme activity modification in erythrocytes. It is widely accepted that erythrocytes with ATP deficiency decrease in deformability, which is associated with erythrocyte removal in RES. ATP depletion is known to produce phosphatidylserine (PS) exposure on plasma membrane by inactivation of ATP-dependent aminophospholipid translocase activity. ${ }^{17)}$ Since PS exposure is a key step for phagocytic removal in various cells including thalassemic erythrocytes ${ }^{18,19)}$ its association with ribavirin-induced hemolytic anemia may arise.

In the present study, we examined morphological transformation and PS exposure in ribavirin-treated erythrocytes in- vitro in association with intracellular ribavirin accumulation and ribavirin-induced hemolytic anemia.

\section{MATERIALS AND METHODS}

Materials and Reagent Solutions Ribavirin, dipyridamole, and 3-methoxycitidine methosulfate were purchased from Sigma-Aldrich (St. Louis, U.S.A.). Annexin V-fluorescein isothiocyanate conjugate (FITC) Kit was purchased from Immunotech, Beckman-Coulter (Miami, U.S.A.). All other reagents and solvents for assay were of analytical or reagent grade and were purchased from Wako Chemicals (Osaka, Japan) and Sigma-Aldrich.

Ribavirin Treatment of Erythrocytes Whole blood was obtained into heparinized tubes from a healthy subject and was centrifuged at $1000 \times \boldsymbol{g}$. Erythrocytes were isolated by removing the supernatant, washed 4 times with 3 volumes of PBS and suspended in HEPES-buffered Tyrode solution (137 mm NaCl, $2.7 \mathrm{~mm} \mathrm{KCl,} 12 \mathrm{~mm}$ HEPES, $1 \mathrm{~mm} \mathrm{MgCl}_{2}$, $2 \mathrm{~mm} \mathrm{CaCl}_{2}$, and $5.6 \mathrm{~mm}$ dextrose; $\mathrm{pH} 7.4$ ) to make the $20 \%$ hematocrit preparation. The erythrocyte suspension was incubated with ribavirin $(1 \mathrm{~mm})$ in the presence/absence of dipyridamole $(25 \mu \mathrm{M})$ at $37^{\circ} \mathrm{C}$.

Determination of Ribavirin Ribavirin concentrations including phosphorylated metabolites in erythrocytes were determined by high-performance liquid chromatography (HPLC) as previously described. ${ }^{11,20)}$ Briefly, incubation mixture was divided into two portions, one for determining ribavirin concentration in supernatant $\left(C_{\text {sup }}\right)$ and the other for that in whole sample $\left(C_{\mathrm{w}}\right)$. Both samples were added with internal standard (IS) and treated with phenyl boronic acid (PBA) column (Bond Elute PBA; Varian, Palo Alto, U.S.A.) to extract ribavirin and IS. Whole sample was subjected to acid phosphatase (Sigma-Aldrich) digestion to hydrolyze the phosphorylated metabolites to ribavirin prior to PBA column extraction. The extracts were analyzed by HPLC (model 8020 system, Tosoh, Tokyo, Japan) equipped with a C18 re- 
verse-phase column (TSK-Gel ODS-80Ts, Tosoh). The detection wavelength was set at $225 \mathrm{~nm}$. The mobile phase solvent, $10 \mathrm{~mm}$ ammonium phosphate buffer $(\mathrm{pH} 2.5)$, was pumped out at a flow rate of $1.0 \mathrm{ml} / \mathrm{min}$. The concentration of ribavirin in erythrocytes $\left(C_{\mathrm{rbc}}\right)$ was calculated by the following equation: $C_{\mathrm{rbc}}=\left[C_{\mathrm{w}}-C_{\text {sup }}(1-\mathrm{Hct})\right] / \mathrm{Hct}$, where Hct is the hematocrit (the value is 0.2 ).

Microscopic Assessment Morphological transformation of erythrocytes was compared among the preparations: nontreated, ribavirin alone, dipyridamole plus ribavirin, and dipyridamole alone following $27-\mathrm{h}$ incubation at $37^{\circ} \mathrm{C}$. Microscopic assessment was conducted with Wright-stained smears of the cells. Thin smears were immediately prepared from incubated erythrocytes using clean transparent glass slides. The smears were air-dried at room temperature, stained through standard Wright's procedure, and examined by light microscopy. The erythrocytes were counted under $\times 400$ magnification. For each sample, 150-300 cells were studied.

Flow Cytometric Analyses and Detection of PS Exposure PS exposure was measured by binding of FITClabeled annexin V using the Annexin V-FITC Kit. Briefly, incubated erythrocytes were resuspended in 1000 volume of binding buffer (137 mM NaCl, $2.7 \mathrm{~mm} \mathrm{KCl}, 12 \mathrm{~mm}$ HEPES, $1 \mathrm{mM} \mathrm{MgCl}_{2}$, and $2 \mathrm{mM} \mathrm{CaCl}_{2} ; \mathrm{pH}$ 7.4). Annexin V-FITC solution $(5 \mu \mathrm{l})$ was added to $495 \mu \mathrm{l}$ of suspension and incubated for $10 \mathrm{~min}$ on ice in the dark. The cells were analyzed by flow cytometry using COULTER ${ }^{\circledR}$ EPICS $^{\circledR}$ XLTM $^{\text {TM }}$ Flow Cytometer (Beckman Coulter, Miami, U.S.A.) and WinMDI software (Joseph Trotter, Scripps Research Institute, La Jolla, U.S.A.). Forward scatter (FS), side scatter (SS), and fluorescence intensity data were collected from 50000 events/each sample aliquot. The percentage of annexin V-positive cells was determined from the fluorescence signal in excess of that obtained from an unlabeled negative control sample aliquot.

\section{RESULTS AND DISCUSSION}

Ribavirin including phosphorylated metabolites was accumulated in the erythrocytes with the plateau level of $1361 \mu \mathrm{M}$ when incubated with $1 \mathrm{~mm}$ of ribavirin for 18-h. Dipyridamole $(25 \mu \mathrm{M})$, an inhibitor of es-type nucleoside transporter, reduced accumulation of ribavirin by $40.7 \%(807 \mu \mathrm{M})$. These intracellular levels for ribavirin corresponded to the steady state erythrocyte levels $(800-1600 \mu \mathrm{M})$ in HCV patients receiving ribavirin. ${ }^{9,10)}$ Since erythrocyte ribavirin concentration $>1000 \mu \mathrm{M}$ has been reported a risk for ribavirininduced anemia, ${ }^{10}$ it is interesting to compare the ribavirintreated erythrocytes with and without dipyridamole in terms of intracellular ribavirin of lower and higher than $1000 \mu \mathrm{M}$, respectively.

Microscopic assessment revealed that transformation into echinocytic form was observed in $86.4 \%$ of erythrocytes treated with ribavirin (Table 1, Fig. 1B), whereas little change was observed in control (Table 1, Fig. 1A) and dipyridamole alone (Table 1). Pre-treatment with dipyridamole decreased the ribavirin-induced echinocytic transformation to $20.0 \%$ (Table 1, Fig. 1C). Flow cytometry revealed that erythrocytes treated with ribavirin showed a relative decrease in

Table 1. Morphological Transformation and Percent Annexin V-Stained Cells of Four Erythrocyte Preparations: Non-treated (Control), Ribavirin Alone, Dipyridamole Plus Ribavirin, and Dipyridamole Alone

\begin{tabular}{lrccc}
\hline \hline \multirow{2}{*}{ Treatment } & \multicolumn{3}{c}{$\begin{array}{c}\text { Erythrocyte } \\
\text { morphology (\%) }\end{array}$} & $\begin{array}{c}\text { Annexin } \\
\text { V-stained cells } \\
(\%)^{a)}\end{array}$ \\
\cline { 2 - 4 } & Normal & Echinocytic & Other & \\
\hline Control & 94.9 & 0 & 5.1 & $0.87 \pm 0.05$ \\
Ribavirin & 6.8 & 86.4 & 6.8 & $2.15 \pm 0.08$ \\
Ribavirin+dipyridamole & 77.4 & 20.0 & 2.6 & $0.62 \pm 0.04$ \\
Dipyridamole & 98.7 & 0.6 & 0.6 & $0.62 \pm 0.02$ \\
\hline
\end{tabular}

a) Data were expressed as mean \pm S.D. of three independent experiments.
A

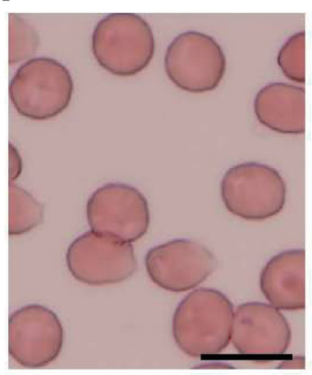

D

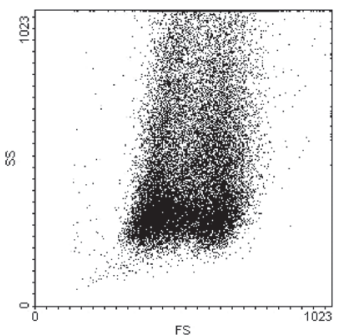

B

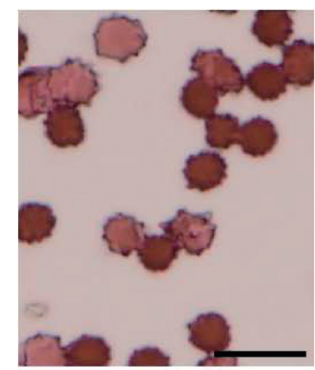

E

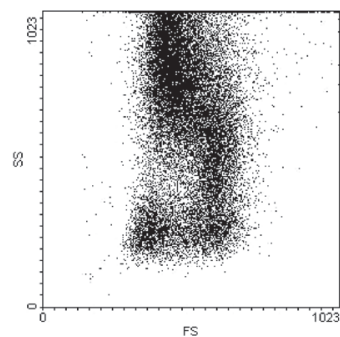

C

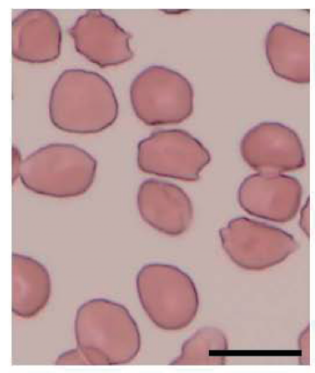

$\mathbf{F}$

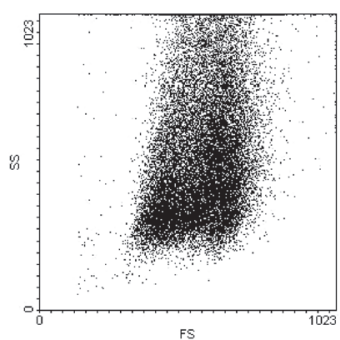

Fig. 1. Microphotographs $(\mathrm{A}-\mathrm{C})$ and Dot Plots of FS (Horizontal Axis; Arbitrary Units) and SS (Vertical Axis; Arbitrary Units) (D-F) of Three Erythrocyte Preparations, Non-treated (Control: A, D), Ribavirin Alone (B, E) and Dipyridamole Plus Ribavirin (C, F)

Bar in each figure indicates $10 \mu \mathrm{m}(\mathrm{A}-\mathrm{C})$. Data are representative of three experiments. 
FS with upward shift in SS (Fig. 1E) compared with control (Fig. 1D), while treatment with dipyridamole alone (not shown) and dipyridamole plus ribavirin (Fig. 1F) showed little shift in the FS and SS profile. Mean FS for non-treated, ribavirin alone, dipyridamole plus ribavirin, and dipyridamole alone was 541, 499, 560, and 564, respectively and SS, 539, 701, 578, and 579, respectively.

Echinocytic transformation is commonly observed in erythrocytes with ATP deficiency. ${ }^{16)}$ Since these cells have less deformability and are easily removed in RES, they are difficult to detect in circulating blood in vivo. Although echinocytes have not been reported in patients receiving ribavirin so far, a decrease in mean cell volume of erythrocyte and mean cell $\mathrm{Hb}$ was found during ribavirin treatment, ${ }^{21}$ suggesting that morphological change in erythrocyte is induced by ribavirin treatment. The present in vitro study revealed for the first time that intracellular ribavirin accumulation induced echinocytic transformation. Flow cytometric analysis demonstrated that ribavirin-treated erythrocytes had a decrease in FS with prominent upward shift in SS compared with control, presumably supporting the morphological change shown by microscopy (Fig. 1).

The ratio of PS-exposing erythrocytes was increased by ribavirin treatment $(2.15 \%)$ compared with control $(0.87 \%)$ and dipyridamole alone (0.62\%) (Table 1$)$. Ribavirin-induced PS exposure was eliminated by inhibiting intracellular ribavirin accumulation with dipyridamole $(0.62 \%$; Table 1$)$. These observations suggest that intracellular ribavirin also induced PS exposure on the outer leaflet of erythrocyte plasma membrane.

Both echinocytic transformation and PS exposure are associated with intracellular ATP reduction in erythrocytes. ${ }^{16,17)}$ De Franceschi et al. reported that $1 \mathrm{~mm}$ of ribavirin produced $55 \%$ reduction of erythrocyte ATP levels and induced oxidation damage on cell membrane by inactivating the ATPdependent anti-oxidation system, hexose monophosphate shunt. ${ }^{15)}$ Aminophospholipid translocase, which maintains PS at the inner leaflet of plasma membrane, ${ }^{17)}$ is also one of the ATP-dependent enzymes. It is well known that inactivation of this enzyme produces PS exposure on the outer leaflet of plasma membrane, which is recognized by macrophages possessing PS receptor. ${ }^{2-25)}$ In our in-vitro system, it was suggested that PS exposure on the erythrocyte membrane was induced by intracellular accumulation of ribavirin in erythrocytes.

Although the change in PS exposure was smaller than that for echinocytic formation, PS exposure possibly participates in ribavirin-induced anemia. Bonomini et al. found that the ratio for PS-exposing erythrocytes was increased in patients with chronic renal failure (CRF) $(2.32 \%)$ and patients on hemodialysis (HD) $(3.06 \%)$ compared with control subjects $(0.68 \%){ }^{26)}$ They proposed that increase in PS exposure for $\mathrm{CRF}$ and HD patients might be associated with anemia, which is common in these individuals. Since the ratio for PS exposure on ribavirin-treated erythrocytes $(2.15 \%)$ was comparable to that for CRF patients, PS exposure may be attributable to ribavirin-induced hemolytic anemia, even though the change in the ratio was small.

We conclude that intracellular ribavirin increases the number of PS-exposing erythrocytes and echinocytic transformation, both of which may accelerate erythrophagocytosis in
RES, as well as oxidation damage, in patients treated with ribavirin.

Acknowledgements We greatly thank for Dr. Y. Matsuzaki and Dr. Y. Inoue for useful discussion on ribavirininduced anemia in IFN and ribavirin combination therapy. This research was supported by Grant-in-Aid for Scientific Research (No. 20590534), the Ministry of Education, Culture, Sports, Science and Technology of Japan.

\section{REFERENCES}

1) Sidwell R. W., "Ribavirin: In vitro antiviral activity. A Broad Spectrum Antiviral Agent," ed. by Smith R. A., Kirkpatrick W., Academic Press, London, pp. 23-42, 1980.

2) Sidwell R. W., Huffman J. H., Khare G. P., Allen L. B., Witkowski J. T., Robins R. K., Science, 177, $705-706$ (1972).

3) Manns M. P., McHutchison J. G., Gordon S. C., Rustgi V. K., Shiffman M., Reindollar R., Goodman Z. D., Koury K., Ling M., Albrecht J. K., Lancet, 358, 958 - 965 (2001).

4) McHutchison J. G., Gordon S. C., Schiff E. R., Shiffman M. L., Lee W. M., Rustgi V. K.,. Goodman Z. D., Ling M. H., Cort S., Albrecht J. K., N. Engl. J. Med., 339, 1485-1492 (1998).

5) Reichard O., Norkrands G., Fryden A., Braconier J. H., Sonnerborg A., Weiland O., Lancet, 351, 83-87 (1998).

6) Chang C. H., Chen K. Y., Lai M. Y., Chan K. A., Aliment Pharmacol. Ther, 16, 1623-1632 (2002).

7) Fried M. W., Hepatology, 36, S237-244 (2002).

8) Gaeta G. B., Precone D. F., Felaco F. M., Bruno R., Spadaro A., Stornaiuolo G., Stanzione M., Ascione T., De Sena R., Campanone A., Filice G., Piccinino F., Aliment Pharmacol. Ther, 16, 1633-1639 (2002).

9) Homma M., Matsuzaki Y., Inoue Y., Shibata M., Mitamura K., Tanaka N., Kohda Y., Clin. Gastroenterol. Hepatol., 2, 337-339 (2004).

10) Inoue Y., Homma M., Matsuzaki Y., Shibata M., Matsumura T., Ito T., Kohda Y., Hepatol. Res., 34, 23-27 (2006).

11) Inoue Y., Homma M., Matsuzaki Y., Shibata M., Matsumura T., Ito T., Mitamura K., Tanaka N., Kohda Y., Antimicrob. Agents Chemother, 48, 3813-3816 (2004).

12) Lertora J. J., Rege A. B., Lacour J. T., Ferencz N., George W. J., VanDyke R. B., Agrawal K. C., Clin. Pharmacol. Ther, 50, 442-549 (1991).

13) Jarvis S. M., Thorn J. A., Glue P., Br. J. Pharmacol., 123, 1587-1592 (1998).

14) Page T., Connor J. D., Int. J. Biochem., 22, 379-383 (1990).

15) De Franceschi L., Fattovich G., Turrini F., Ayi K., Brugnara C., Manzato F., Noventa F., Stanzial A. M., Solero P., Corrocher R., Hepatology, 31, 997-1004 (2000).

16) Backman L., J. Cell Sci., 80, 281-298 (1986).

17) Paulusma C. C., Oude Elferink R. P., Biochim. Biophys. Acta, 1741 $11-24$ (2005).

18) Kuypers F. A., Yuan J., Lewis R. A., Snyder L. M., Kiefer C. R., Bunyaratvej A., Fucharoen S., Ma L., Styles L., de Jong K., Schrier S. L., Blood, 91, 3044-3051 (1998).

19) McEvoy L., Williamson P., Schlegel R. A., Proc. Natl. Acad. Sci. U.S.A., 83, 3311-3315 (1986).

20) Homma M., Jayewardene A. L., Gambertoglio J., Aweeka F. T., Antimicrob. Agents Chemother., 43, 2716-2719 (1999).

21) Tanaka H., Miyano N., Ueda H., Fukui K., Ichinose M., Clin. Exp. Med., 5, 190-195 (2005).

22) Fadok V. A., Bratton D. L., Rose D. M., Pearson A., Ezekewitz R. A., Henson P. M., Nature (London), 405, 85-90 (2000).

23) Miyanishi M., Tada K., Koike M., Uchiyama Y., Kitamura T., Nagata S., Nature (London), 450, 435-439 (2007).

24) Park D., Tosello-Trampont A. C., Elliott M. R., Lu M., Haney L. B., Ma Z., Klibanov A. L., Mandell J. W., Ravichandran K. S., Nature (London), 450, 430-434 (2007).

25) Park S. Y., Jung M. Y., Kim H. J., Lee S. J., Kim S. Y., Lee B. H., Kwon T. H., Park R. W., Kim I. S., Cell Death Differ., 15, 192-201 (2008).

26) Bonomini M., Sirolli V., Settefrati N., Dottori S., Di Liberato L., Arduini A., J. Am. Soc. Nephrol., 10, 1982-1990 (1999) 